\title{
Aspectos biológicos de Argyrotaenia sphaleropa (Meyrick 1909) (Lepidoptera: Tortricidae) em Dietas Artificiais com Diferentes Fontes Proteicas
}

\author{
Biological aspects of Argyrotaenia sphaleropa (Meyrick, 1909) \\ (Lepidoptera: Tortricidae) in artificial diets with different protein sources
}

\author{
Silvana Manfredi-Coimbra ${ }^{1}$ Mauro Silveira Garcia ${ }^{2}$ \\ Alci Enimar Loeck ${ }^{2}$ Marcos Botton ${ }^{3}$ Josemar Foresti $^{4}$
}

RESUMO

Estudaram-se aspectos da biologia de Argyrotaenia sphaleropa Meyrick em dietas artificiais com diferentes fontes proteicas: $D_{1}$-feijão branco, germe de trigo, proteína de soja e caseína; $D_{2}$-feijão carioca e levedura de cerveja e $D_{3}$-feijão carioca, levedura de cerveja e germe de trigo, avaliando-se a duração e viabilidade e todas as fases de desenvolvimento desse inseto (ovo, lagarta, pré-pupa e pupa) e do ciclo total (ovo-adulto), razão sexual, peso de pupas, fecundidade, longevidade e tabela de vida de fertilidade. Os experimentos foram conduzidos em laboratório a $25 \pm 1^{\circ} \mathrm{C}, 65 \pm 10 \% \mathrm{UR} e$ fotofase de 14 horas. A duração da fase de ovo foi de 6,6 dias nas três dietas. A maior duração das fases lagarta e pré-pupa foi em $D_{1}$ e de pupa em $D_{2}$, resultando em maior duração do ciclo total nestas duas dietas (30,9 e 30,8 dias). A viabilidade total foi superior a $62 \%$ em todas as dietas, independente da fonte proteica. $O$ número de ínstares foi de quatro a cinco nas três dietas. A menor fecundidade foi observada em $D_{1}$. Através da tabela de vida de fertilidade, a dieta $D_{3}$ foi a mais adequada para criação de A. sphaleropa por ter proporcionado menor duração de desenvolvimento (T), maior razão finita de aumento ( $\lambda$ ) e viabilidade total superior a $75 \%$.

Palavras-chave: dieta artificial, tabela de vida de fertilidade.

\section{ABSTRACT}

Biology aspects of Argyrotaenia sphaleropa Meyrick fed on artificial diets with different protein sources were studied: $D_{1}$-white bean, wheat germ, soybean protein and casein; $D_{2}$-common bean and yeast and $D_{3}$-common bean, yeast and wheat germ, evaluating the duration and viability of all developmental stages (egg, larval, prepupa and pupa) and of the total cycle (egg-adult), sex ratio, pupa weight, fecundity, longevity and life table of fertility. Tests were conducted in the laboratory at $25 \pm 1{ }^{\circ} \mathrm{C}, 65 \pm 10 \% \mathrm{RH}$ and $14 \mathrm{~h}$ of photophase. Duration of the egg stage was 6.6 days on all diets. The longest duration of larval and prepupal stages on $D_{1}$ and pupal stages on $D_{2}$, resulting in a longer duration of the total cycle on these two diets (30,9 and 30,8 days). The total viability was higher than $62 \%$ on all diets, and there was no statistical difference among the treatments. The number of instars was four or five on all treatments. The lowest fecundity was observed in $D_{l}$. Based on the fertility life table, $D_{3}$ was the most suitable diet for rearing $A$. sphaleropa, due to the lowest development time $(T)$, the highest finite increasing rate $(\lambda)$, and total viability exceeding $75 \%$.

Key words: artificial diet, fertility life table.

\section{INTRODUÇÃO}

Os primeiros registros de ocorrência da lagarta dos racemos, Argyrotaenia sphaleropa no Brasil foram feitos por BIEZANKO (1961). Trata-se de um tortricídio polífago, comum no Uruguai, onde os prejuízos são freqüentes nas culturas da maçã e da videira (BENTANCOURT et al., 1988). A distribuição é ampla ocorrendo na América do Sul, incluindo Bolívia, Peru, Argentina e Brasil (BENTANCOURT \& SCATONI, 1995). As lagartas podem alimentar-se de brotações, folhas, flores e frutos de ampla variedade de plantas. Entre os principais hospedeiros, BIEZANKO et al. (1957) citam fruteiras, como maçã (Pyrus communis), pêra (Pyrus communis) e videira (Vitis vinifera), e ornamentais, dentre elas, rosa (Rosa sp.), ligustre

${ }^{1}$ Engenheiro Agrônomo, Doutorando em Entomologia, Universidade Federal de Pelotas (UFPel), Rua Marechal Deodoro, 715/ 305, Centro, 96020-220, Pelotas, RS. E-mail: silvana.coimbra@pop.com.br. Autor para correspondência.

${ }^{2}$ Engenheiro Agrônomo, Doutor, Professor do Departamento de Fitossanidade, Faculdade de Agronomia Eliseu Maciel (FAEM), UFPel.

${ }^{3}$ Engenheiro Agrônomo, Doutor, Pesquisador da Empresa Brasileira de Pesquisa Agropecuária (EMBRAPA), Centro Nacional de Pesquisa de Uva e Vinho (CNPUV).

${ }^{4}$ Engenheiro Agrônomo, Mestre em Entomologia(FAEM), UFPel. 
(Ligustrum lucidum), jasmim (Gardenia jasminoides) e madreselva (Lonicera japonica).

A ocorrência de A. sphaleropa no Uruguai tem sido associada aos desequilíbrios ocasionados pelo uso indevido de inseticidas químicos nos cultivos de videira (BENTANCOURT \& SCATONI, 1995). No Brasil, foi inicialmente observada no estado de São Paulo (BENTANCOURT \& SCATONI, 1986) e também ao sul do Rio Grande do Sul (BIEZANKO, 1961). A partir das safras de 1998/1999 de caqui, Diospyros kaki L., tem sido registrada em Bento Gonçalves/RS em alta população atacando frutos, onde as lagartas raspam a epiderme superficialmente, próximo à cavidade peduncular, inviabilizando o fruto para comercialização devido ao aspecto e à aceleração da maturação. O ataque é visualizado a partir da fase de crescimento dos frutos, porém, os danos são observados, principalmente, nos meses de março a abril, período em que as cultivares mais plantadas, como a Fuyu, apresentam frutos em fase de maturação. Além de os prejuízos causados na cultura do caqui serem um empecilho para o desenvolvimento da cultura, o aumento populacional do inseto em Bento Gonçalves e localidades adjacentes é preocupante, pois se trata de uma região essencialmente produtora de uva, principal hospedeira da praga em outros países.

Tendo em vista a escassez de informações sobre aspectos biológicos e hábitos de A. sphaleropa, e seu potencial de dano para fruteiras e plantas ornamentais, o trabalho foi desenvolvido com o objetivo de avaliar o efeito de três dietas artificiais com fontes protéicas utilizadas na rotina do Laboratório de Biologia de Insetos da UFPel, sobre a biologia de A. sphaleropa .

\section{MATERIAL E MÉTODOS}

O trabalho foi desenvolvido no Laboratório de Biologia de Insetos do Departamento de Fitossanidade, da Faculdade de Agronomia "Eliseu Maciel" (FAEM), Universidade Federal de Pelotas, localizada no município de Capão do Leão/RS. Utilizaram-se insetos procedentes de pomares de caqui cultivados no município de Bento Gonçalves e criados em condições controladas de temperatura, umidade relativa e fotoperíodo $\left(25 \pm 1^{\circ} \mathrm{C}, 65 \pm 10 \%\right.$ e $\left.14: 10 \mathrm{~h}\right)$.

Foram mantidas três criações em diferentes dietas artificiais por quatro gerações a fim de eliminar o efeito da modificação da alimentação natural para artificial. As dietas foram elaboradas com diferentes fontes protéicas: feijão branco, germe de trigo, proteína de soja e caseína $\left(D_{1}\right)$, sugerida por PARRA (1992); feijão carioca, levedura e caseína $\left(\mathrm{D}_{2}\right)$, sugerida por
PARRA et al. (1995); e feijão carioca, levedura e germe de trigo $\left(\mathrm{D}_{3}\right)$, sugerida por PARRA (1992). As dietas $\mathrm{D}_{1}$ e $\mathrm{D}_{3}$ são recomendadas para criação artificial de Noctuidae (Anticarsia gemmatalis Hübner e Spodoptera frugiperda Smith, respectivamente) e a $\mathrm{D}_{2}$ para Tortricidae (Bonagota cranaodes Meyrick) (Tabela 1). Foram comparados os efeitos das diferentes fontes proteicas sobre os seguintes aspectos biológicos: duração e viabilidade das fases de ovo, lagarta, pré-pupa, pupa e ciclo total (ovo-adulto); número de ínstares; razão sexual; peso de pupas (macho e fêmea) com $24 \mathrm{~h}$; fecundidade e longevidade de adultos.

Para o estudo do desenvolvimento embrionário e viabilidade de ovos, foi utilizado material oriundo das criações de manutenção conduzidas nas três dietas. Três massas de 50 ovos foram transferidas individualmente para tubos de vidro de $2,5 \times 8,5 \mathrm{~cm}$, totalizando 150 ovos para cada dieta. No interior de cada tubo, colocou-se um pedaço de papel filtro umedecido com água destilada para manutenção da umidade. Os tubos foram fechados com filme de PVCe os ovos incubados em câmara climatizada regulada a $25 \pm 1^{\circ} \mathrm{C}, 65 \pm 10 \%$ UR e fotofase de $14 \mathrm{~h}$.

Lagartas recém-eclodidas, provenientes de posturas das três criações artificiais $\left(D_{1}, D_{2}\right.$ e $\left.D_{3}\right)$

Tabela 1 - Constituição das dietas para Anticarsia gemmatalis, Bonagota cranaodes e Spodoptera frugiperda testadas para criação de Argyrotaenia sphaleropa.

\begin{tabular}{|c|c|c|c|}
\hline \multirow{3}{*}{ Composição } & \multicolumn{3}{|c|}{ Dietas } \\
\hline & \multirow{2}{*}{$\begin{array}{c}\text { A. gemmatalis } \\
\qquad \mathrm{D}_{1}\end{array}$} & \multirow{2}{*}{$\begin{array}{c}\text { A. cranaodes } \\
\qquad \mathrm{D}_{2}\end{array}$} & \multirow{2}{*}{$\begin{array}{c}\text { S. frugiperda } \\
\mathrm{D}_{3}\end{array}$} \\
\hline & & & \\
\hline Feijão branco & $75,00 \mathrm{~g}$ & - & - \\
\hline Feijão carioca & - & $347,00 \mathrm{~g}$ & $247,50 \mathrm{~g}$ \\
\hline Germe de trigo & $60,00 \mathrm{~g}$ & - & $118,80 \mathrm{~g}$ \\
\hline Caseína & $30,00 \mathrm{~g}$ & - & - \\
\hline Levedura de cerveja & $30,00 \mathrm{~g}$ & $52,00 \mathrm{~g}$ & $75,75 \mathrm{~g}$ \\
\hline Farinha de soja & $30,00 \mathrm{~g}$ & - & - \\
\hline Ácido ascórbico & $3,60 \mathrm{~g}$ & $4,90 \mathrm{~g}$ & $7,65 \mathrm{~g}$ \\
\hline Ácido sórbico & $1,80 \mathrm{~g}$ & $1,60 \mathrm{~g}$ & $2,47 \mathrm{~g}$ \\
\hline Nipagin & $1,50 \mathrm{~g}$ & $3,30 \mathrm{~g}$ & $4,72 \mathrm{~g}$ \\
\hline Tetraciclina & $113,00 \mathrm{mg}$ & $0,80 \mathrm{mg}$ & - \\
\hline Formaldeído & $3,60 \mathrm{ml}$ & $3,20 \mathrm{ml}$ & $4,70 \mathrm{ml}$ \\
\hline Solução vitamínica ${ }^{1}$ & $9,00 \mathrm{ml}$ & $40,60 \mathrm{ml}$ & - \\
\hline Ácido propiônico & - & $1,20 \mathrm{ml}$ & - \\
\hline Agar & $23,00 \mathrm{~g}$ & $21,00 \mathrm{~g}$ & $30,75 \mathrm{~g}$ \\
\hline Água & $1200,00 \mathrm{ml}$ & $1000,00 \mathrm{ml}$ & $1792,50 \mathrm{ml}$ \\
\hline
\end{tabular}

${ }^{1 /}$ Niacinamida 1,0g; Pantotenato de cálcio 1,0g; Riboflavina 0,5g; Tiamina $0,25 \mathrm{~g}$; Piridoxina $0,25 \mathrm{~g}$; Ácido fólico $0,25 \mathrm{~g}$; Biotina $0,02 \mathrm{~g}$; Vitamina $\mathrm{B}_{12} 0,002 \mathrm{~g}$.

Ciência Rural, v.35, n.2, mar-abr, 2005. 
mantidas em laboratório, foram individualizadas em tubos de vidro de $2,5 \times 8,5 \mathrm{~cm}$, previamente esterilizados e tamponados com algodão hidrófobo, contendo dieta artificial. Para cada dieta, foram avaliadas 150 lagartas (repetições), mantidas em câmara climatizada nas mesmas condições do período embrionário. As pupas foram pesadas $24 \mathrm{~h}$ após sua formação, separadas por sexo e, posteriormente, individualizadas em tubos de vidro de $2,5 \times 8,5 \mathrm{~cm}$ contendo papel filtro umedecido com água destilada. O acompanhamento do desenvolvimento do inseto foi diário, registrando-se a duração e a viabilidade das fases de lagarta, prépupa, pupa e do ciclo total (ovo-adulto). O delineamento experimental foi inteiramente casualizado, os resultados foram submetidos à análise de variância e as médias comparadas pelo teste de Tukey ao nível de 5\% de probabilidade (SAS, 1998).

$\mathrm{O}$ número de ínstares foi determinado a partir da medição diária da cápsula cefálica de 30 lagartas de cada tratamento, utilizadas para avaliação da duração da fase de lagarta. As medições foram feitas através do tubo de vidro, utilizando-se a ocular micrométrica Wild MMS 235, acoplada a um microscópio estereoscópico, adotando-se o método de distribuição de freqüências proposto por HADDAD et al. (1995). As médias foram comparadas pelo teste de Tukey em nível de 5\% de probabilidade (SAS, 1998).

A fecundidade e a longevidade dos adultos de A. sphaleropa foram avaliadas individualizandose 25 casais por tratamento, formados a partir de adultos emergidos no mesmo dia, obtidos nas três dietas. Os casais foram acondicionados em gaiolas de PVC transparente semiflexível (copos invertidos), com capacidade de $200 \mathrm{ml}$, contendo na sua extremidade superior um pequeno orifício tamponado com filó. A extremidade inferior foi fechada com a tampa do próprio recipiente, a qual foi perfurada no centro, para inserção do tubo contendo solução de mel a $10 \%$, fornecida como alimento aos adultos. As posturas foram marcadas diariamente, contornando o local da gaiola onde foram colocadas e, a cada dois dias, retiradas. Diariamente a mortalidade foi registrada para estimativa da longevidade média de machos e fêmeas. O delineamento experimental foi inteiramente casualizado com 20 repetições, sendo as médias comparadas pelo teste de Tukey em nível de 5\% de probabilidade. A partir desses dados, foram calculadas as tabelas de vida de fertilidade para A. sphaleropa em cada dieta (SILVEIRA NETO et al., 1976), onde: $r_{\mathrm{m}}=$ $\log \mathrm{R}_{0} / \mathrm{T} * 0,4343 ; \mathrm{R}_{0}=\sum \mathrm{mx} * \mathrm{~lx} ; \mathrm{T}=\sum \mathrm{mx} * \mathrm{~lx} * \mathrm{x} / \sum \mathrm{mx}^{*} \mathrm{~lx}$ e $\mathrm{l}=\operatorname{antilog}\left(\mathrm{r}_{\mathrm{m}} * 0,4343\right)$, sendo $\mathrm{r}_{\mathrm{m}}$ a capacidade inata de aumentar em número a cada geração; $\mathrm{R}_{0}$, o número de vezes que cada espécie pode aumentar a cada geração; $\mathrm{T}$, o intervalo de tempo entre cada geração em dias ou período médio que vai do nascimento dos pais ao nascimento dos descendentes e 1 , o número de indivíduos adicionados à população, por fêmea, por semana, que darão fêmeas.

\section{RESULTADOS E DISCUSSÃO}

A duração do período embrionário foi semelhante nas três dietas (Tabela 2). BENTANCOURT \& SCATONI (1986) obtiveram duração semelhante para essa espécie (6,16 dias). Estes resultados estão próximos aos obtidos para outras espécies do mesmo gênero: 7,2 dias para A. velutinana (HAWTHORNE et al., 1988) e 7,3 dias para A. salubricola

Tabela 2 - Duração (dias) e viabilidade percentual ( \pm EP) para ovo, lagarta, pré-pupa, pupa e ciclo total (ovo-adulto) e peso de pupas (mg) machos e fêmeas de Argyrotaenia sphaleropa, criada em dietas artificiais formuladas com fontes protéicas diferenciadas $\left(\mathrm{D}_{1}\right.$ : feijão branco, germe de trigo, proteína de soja e caseína, $\mathrm{D}_{2}$ : feijão carioca e levedura de cerveja; $\mathrm{D}_{3}$ : feijão carioca, levedura de cerveja e germe de trigo). Temperatura: $25 \pm 1^{\circ} \mathrm{C}$, UR: $65 \pm 10 \%$, Fotofase: $14 \mathrm{~h}$. Laboratório de Biologia de Insetos, FAEM/UFPel $(n=150)$.

\begin{tabular}{|c|c|c|c|c|c|c|c|c|}
\hline & \multicolumn{4}{|c|}{ Duração (dias) } & \multicolumn{4}{|c|}{ Viabilidade (\%) } \\
\hline & $\mathrm{D}_{1}$ & $\mathrm{D}_{2}$ & $\mathrm{D}_{3}$ & Média $(\mathrm{CV})^{2}$ & $\mathrm{D}_{1}$ & $\mathrm{D}_{2}$ & $\mathrm{D}_{3}$ & Média $(\mathrm{CV} \%)^{2}$ \\
\hline Ovo & $6,6 \pm 0,23 \mathrm{a}$ & $6,6 \pm 0,12 \mathrm{a}$ & $6,6 \pm 0,11 \mathrm{a}$ & $6,6(12,3)$ & $88,5 \pm 1,22 \mathrm{a}$ & $88,5 \pm 0,69 \mathrm{a}$ & $92,0 \pm 0,83 \mathrm{a}$ & $89,7(4,4)$ \\
\hline Lagarta & $16,7 \pm 0,12 \mathrm{a}$ & $16,4 \pm 0,14 \mathrm{a}$ & $15,4 \pm 0,11 b$ & $16,2(10,5)$ & $89,5 \pm 1,14 \mathrm{a}$ & $85,5 \pm 1,60 \mathrm{a}$ & $84,0 \pm 0,90 \mathrm{a}$ & $86,3(8,0)$ \\
\hline Pré-pupa & $1,2 \pm 0,03 \mathrm{a}$ & $1,0 \pm 0,01 \mathrm{~b}$ & $1,1 \pm 0,02 \mathrm{~b}$ & $1,1(32,5)$ & $100,0 \mathrm{a}$ & $100,0 \mathrm{a}$ & $100,0 \mathrm{a}$ & $100,0(0,0)$ \\
\hline Pupa & $6,5 \pm 0,07 \mathrm{~b}$ & $6,9 \pm 0,06 \mathrm{a}$ & $7,0 \pm 0,06 \mathrm{a}$ & $6,8(11,7)$ & $79,4 \pm 1,75 b$ & $97,1 \pm 0,48 \mathrm{a}$ & $98,1 \pm 0,57 \mathrm{a}$ & $91,7(7,8)$ \\
\hline Ciclo total & $30,9 \pm 0,16 \mathrm{a}$ & $\begin{array}{r}30,8 \pm 0,13 \text { a } \\
\text { Mach }\end{array}$ & $\begin{array}{l}30,2 \pm 0,13 \mathrm{~b} \\
\mathrm{~s}(\mathrm{mg})\end{array}$ & $30,6(5,8)$ & $62,9 \pm 1,73 a$ & $\begin{array}{r}73,5 \pm 1,58 \mathrm{a} \\
\text { Fêm }\end{array}$ & $\begin{array}{l}75,8 \pm 0,70 \text { a } \\
\text { as (mg) }\end{array}$ & $68,8(13,3)$ \\
\hline Peso de pupas & $19,5 \pm 0,22 \mathrm{a}$ & $19,8 \pm 0,19 \mathrm{a}$ & $19,9 \pm 0,22 \mathrm{a}$ & $19,7(19,5)$ & $32,5 \pm 0,27 \mathrm{a}$ & $32,9 \pm 0,26 \mathrm{a}$ & $32,1 \pm 0,27 \mathrm{a}$ & $32,4(19,6)$ \\
\hline
\end{tabular}

${ }^{1}$ Médias não seguidas da mesma letra diferem significativamente entre si pelo teste de Tukey em nível de 5\% de probabilidade de erro.

${ }^{2}$ Média geral e coeficiente de variação entre parêntesis. 
(BENTANCOURT \& SCATONI, 1988). Não ocorreu diferença para viabilidade da fase de ovo entre dietas (Tabela 2).

A fase de lagarta teve duração menor em $\mathrm{D}_{3}$, diferindo da observada em $\mathrm{D}_{1}$ e $\mathrm{D}_{2}$ (Tabela 2), cuja duração foi de 16,7 e 16,4 dias, respectivamente, aproximando-se à duração de 17,2 dias obtida por BENTANCOURT \& SCATONI (1986), que utilizaram folhas de videira como substrato alimentar para lagartas de A. sphaleropa. A duração dessa fase é bastante variável de acordo com o hospedeiro; podendo durar cerca de 17 a 25 dias em folhas de macieira coletadas em diferentes estações e 35 a 37 dias nos frutos; ou em média 22 a 25 dias em folhas de videira e 27 a 30 dias na fruta (BENTANCOURT et al., 2003). Durante essa fase, as lagartas permanecem grande parte do tempo escondidas sob uma teia que tecem sobre o corpo. Esse é um hábito comumente observado entre os tortricídeos, que, segundo BENTANCOURT \& SCATONI (1986), mostram uma tendência a permanecer ocultos durante todo o seu desenvolvimento larval, tecendo uma galeria de seda e prendendo-a às pontas de um folíolo da planta hospedeira.

A fase de pré-pupa pôde ser facilmente caracterizada, pois com freqüência a lagarta parou de se alimentar, deslocou-se para o algodão utilizado para tamponar o tubo, onde permaneceu imóvel. Com a segmentação do corpo aparente, assumiu uma coloração verde claro intenso, teceu um casulo de seda à sua volta e, posteriormente, se transformou em pupa. A duração da fase de pré-pupa foi significativamente maior na $\mathrm{D}_{1}$ (Tabela 2). Os resultados obtidos para essa fase foram próximos aos observados por BENTANCOURT \& SCATONI (1986), que em geral é de 1 dia.

A pupa apresentou-se inicialmente com coloração castanha, que progrediu para marrom escura próximo a emergência. A maior duração e menor viabilidade da fase de pupa foram obtidas na dieta $D_{1}$, que possui maior número de fontes protéicas (Tabela 2). Esses resultados foram bastante próximos aos obtidos por BENTANCOURT \& SCATONI (1988) utilizando folhas de videira $(6,4$ dias para fêmeas e 7,1 dias para machos), apesar de que recentemente BENTANCOURT et al. (2003) registraram duração de 7,6 a 7,9 dias para fêmeas e 8,1 a 8,3 dias para machos com folhas do mesmo hospedeiro, variação que pode ser atribuída à utilização de folhas de diferentes variedades e estações do ano. Em folhas e frutos de macieira, a duração variou de 7,1 a 7,7 dias para fêmeas e 8,4 a 8,7 dias para machos (BENTANCOURT et al., 2003).
A viabilidade da fase de lagarta foi superior a $84 \%$ nas três dietas, não diferindo entre si, bem como a viabilidade da fase de pré-pupa, que foi de $100 \%$ nas três dietas e a de pupa, que se manteve elevada em todos os tratamentos (Tabela 2).

A duração do ciclo total (ovo à emergência do adulto) foi menor na dieta $\mathrm{D}_{3}$, sendo que a $\mathrm{D}_{1}$ e a $\mathrm{D}_{2}$ não diferiram e esta foi a única dieta que proporcionou viabilidade total superior a $75 \%$ (Tabela 2). A melhor adequação a $\mathrm{D}_{3}$ pode ser atribuída a três fatores; primeiro, a proporção de nutrientes presentes no alimento, principalmente carboidrato:proteína, afeta o desenvolvimento (SCRIBER \& SLANSKY, 1981) e de acordo com SINGH (1983), este balanceamento é variável com a idade do inseto, o que explica as diferenças de viabilidade entre fases de desenvolvimento observadas. Um segundo fator é que os aminoácidos presentes na dieta como proteínas, são sempre essenciais aos insetos em desenvolvimento e são exigidos em altas concentrações para um crescimento ótimo (PANIZZI \& PARRA, 1991). Outro fator é que o valor de qualquer proteína ingerida pelo inseto, depende do conteúdo de aminoácidos da mesma e da habilidade do inseto em digeri-la (CHAPMANN, 1982). Pode-se supor que a capacidade de $\boldsymbol{A}$. sphaleropa digerir as fontes protéicas testadas, permitiu que o ciclo total do inseto alimentado com $\mathrm{D}_{3}$ fosse completado em menor tempo e maior viabilidade, sendo a única dieta que permitiu viabilidade superior aquela viabilidade total preconizada por SINGH (1983), que considerada o mínimo de $75 \%$ para uma dieta adequadamente balanceada.

O número de fêmeas foi menor do que o de machos nas dietas $D_{2}$ e $D_{3}$, originando, respectivamente, relação sexual de 1:1,3 e 1:1,1. Apenas na $D_{1}$, observou-se uma relação sexual inversa $(1: 0,9)$. Não houve diferença para o peso de pupas machos e fêmeas entre as três dietas (Tabela 2). Quanto ao tamanho, visualmente, as fêmeas apresentam tamanho de pupa expressivamente maior do que os machos, característica comumente observada em lepidópteros (BENTANCOURT \& SCATONI, 1986).

Embora a duração da fase de lagarta tenha sido menor na dieta $\mathrm{D}_{3}$, a redução não refletiu em decréscimo no número de instares, comparativamente às demais dietas, que se manteve de quatro ou cinco nas três dietas (Tabela 3). Esses resultados podem ser caracterizados pelos valores de coeficiente de determinação $\left(\mathrm{R}^{2}\right)$, sempre próximos a 1 e levemente superiores para quatro ínstares, nas dietas $\mathrm{D}_{2}$ e $\mathrm{D}_{3}$. Os valores de razão de crescimento $(\mathrm{K})$, que se encontram dentro dos limites propostos por Dyar $(1,1$

Ciência Rural, v.35, n.2, mar-abr, 2005. 
Tabela 3 - Largura média $( \pm \mathrm{EP})$ de cápsulas cefálicas $(\mathrm{mm})$ para quatro e cinco ínstares, razão de crescimento (K) e coeficiente de determinação $\left(\mathrm{R}^{2}\right)$ para Argyrotaenia sphaleropa criada em dietas artificiais com fontes protéicas diferenciadas $\left(\mathrm{D}_{1}\right.$ : feijão branco, germe de trigo, proteína de soja e caseína, $\mathrm{D}_{2}$ : feijão carioca e levedura de cerveja; $\mathrm{D}_{3}$ : feijão carioca, levedura de cerveja e germe de trigo). Temperatura: $25 \pm 1^{\circ} \mathrm{C}$; UR: $65 \pm 10 \%$, Fotofase: $14 \mathrm{~h}$. Laboratório de Biologia de Insetos, FAEM/UFPel $(n=30)$.

\begin{tabular}{|c|c|c|c|}
\hline Instar & $\mathrm{D}_{1}$ & $\mathrm{D}_{2}$ & $\mathrm{D}_{3}$ \\
\hline Primeiro & $0,26 \pm 0,003$ & $0,27 \pm 0,003$ & $0,26 \pm 0,003$ \\
\hline Segundo & $0,47 \pm 0,003$ & $0,50 \pm 0,003$ & $0,52 \pm 0,006$ \\
\hline Terceiro & $0,76 \pm 0,002$ & $0,74 \pm 0,003$ & $0,81 \pm 0,010$ \\
\hline Quarto & $1,01 \pm 0,003$ & $0,99 \pm 0,001$ & $1,01 \pm 0,002$ \\
\hline $\mathrm{K}$ & 1,47 & 1,40 & 1,39 \\
\hline $\mathrm{R}^{2}$ & 0,99998 & 0,99999 & 0,99997 \\
\hline Primeiro & $026 \pm 0,003$ & $0,23 \pm 0,001$ & $0,23 \pm 0,002$ \\
\hline Segundo & $0,45 \pm 0,003$ & $0,31 \pm 0,002$ & $0,32 \pm 0,001$ \\
\hline Terceiro & $0,51 \pm 0,004$ & $0,57 \pm 0,011$ & $0,55 \pm 0,008$ \\
\hline Quarto & $0,76 \pm 0,003$ & $0,79 \pm 0,010$ & $0,82 \pm 0,011$ \\
\hline Quinto & $1,01 \pm 0,003$ & $0,99 \pm 0,001$ & $1,01 \pm 0,002$ \\
\hline $\mathrm{K}$ & 1,32 & 1,46 & 1,46 \\
\hline $\mathrm{R}^{2}$ & 0,99999 & 0,99995 & 0,99996 \\
\hline
\end{tabular}

a 1,9) e próximos ao valor médio de 1,44 , indicam que ambas as hipóteses formuladas (de 4 ou 5 ínstares) estão corretas. A observação de número de ínstares igual em todas as dietas pode ser atribuída ao fato de não ter sido feita a separação dos sexos para avaliação desse parâmetro. BENTANCOURT \& SCATONI (1986) registraram ocorrência de cinco ou seis ínstares para a mesma espécie, o que possivelmente se deve ao tipo de dieta utilizado, tendo em vista que estes autores criaram o inseto com hospedeiro natural.

Não houve diferença para a longevidade média de adultos machos e fêmeas entre dietas (Tabela 4). As fêmeas viveram de 12,6 $\left(\mathrm{D}_{1}\right)$ a 14,1 dias $\left(\mathrm{D}_{2}\right)$, enquanto os machos viveram ao redor de 12 dias. Contudo, BENTANCOURT \& SCATONI (1986) afirmaram que fêmeas de $\boldsymbol{A}$. sphaleropa apresentam longevidade menor que os machos. Em A. salubricola, a longevidade de machos também é menor do que a das fêmeas (SCATONI \& BENTANCOURT, 1988).

O número de posturas/fêmea foi menor na dieta $\mathrm{D}_{1}$, em média 8,4 e semelhante ao verificado em $\mathrm{D}_{3}$, diferindo apenas do valor observado para $\mathrm{D}_{2}$ (Tabela 4). Entretanto, o número de ovos/postura foi semelhante nas três dietas, e variou de 33,3 $\left(D_{1}\right)$ a 39,5 $\left(\mathrm{D}_{2}\right)$ ovos/postura, resultados superiores aos obtidos por BENTANCOURT \& SCATONI (1986). Embora não tenha ocorrido diferença para o número de ovos/ postura entre as dietas, o número total de ovos foi maior na dieta $D_{2}$ e não diferiu do observado na $D_{3}$. Não ocorreu diferença para duração do período de oviposição entre as dietas, porém, esse parâmetro foi superior ao registrado por BENTANCOURT \& SCATONI (1986), que foi, em média, 3,4 dias. Mesmo não ocorrendo diferença, ao considerar-se a combinação das características longevidade de fêmeas, número de posturas/fêmea, número de ovos/postura, fecundidade e duração do período de oviposição, pode-se sugerir que a dieta $D_{1}$ foi a menos adequada para manutenção de criação de $\boldsymbol{A}$. sphaleropa em laboratório. Por não haver diferenças qualitativas expressivas no conteúdo das três dietas, este efeito possivelmente se deve ao balanceamento de nutrientes. A menor fecundidade, observada na $D_{1}$ foi semelhante àquela verificada na $\mathrm{D}_{3}$ (Tabela 4 ).

O período médio entre o nascimento dos pais de A. sphaleropa ao nascimento dos descendentes calculado através de tabela de vida de fertilidade (Tabela 5), variou em função da dieta utilizada. Na dieta $D_{2}$, foi necessário cerca de um dia a mais para que uma geração se completasse. Essa foi a única dieta cuja fonte de proteína e também energia utilizada não foi o germe de trigo. Os carboidratos são a principal fonte de energia para os insetos, podendo ser convertidos em gorduras para armazenamento e contribuir para a produção de aminoácidos, de modo que os carboidratos, gorduras e proteínas estão envolvidos em ciclos de reações produtoras de energia (PANIZZI \& PARRA, 1991). Neste caso, pode o componente energético do germe trigo presente em $\mathrm{D}_{1} \mathrm{eD}_{3}$, ter exercido um efeito aditivo ao das fontes protéicas, o que ocasionou uma redução na duração média de cada geração. Ainda se tem de considerar, que existem menos fontes proteicas na $\mathrm{D}_{2}$ do que nas demais, o que pode ter interferido no

Ciência Rural, v.35, n.2, mar-abr, 2005. 
Tabela 4 - Longevidade de adultos de Argyrotaenia sphaleropa, número de posturas/fêmea, número de ovos/postura, fecundidade, duração do período de oviposição, em três dietas artificiais com fontes protéicas variáveis $\left(\mathrm{D}_{1}\right.$ : feijão branco, germe de trigo, proteína de soja e caseína, $\mathrm{D}_{2}$ : feijão carioca e levedura de cerveja; $\mathrm{D}_{3}$ : feijão carioca, levedura de cerveja e germe de trigo). Temperatura: $25 \pm 1^{\circ} \mathrm{C}$; UR: $65 \pm 10 \%$, Fotofase: $14 \mathrm{~h}$.

\begin{tabular}{|c|c|c|c|c|c|c|}
\hline Dieta & $\begin{array}{l}\text { Longevidade de } \\
\text { fêmeas }\end{array}$ & $\begin{array}{l}\text { Longevidade de } \\
\text { machos }\end{array}$ & $\begin{array}{c}\text { Número de } \\
\text { posturas/fêmea }\end{array}$ & $\begin{array}{l}\text { Número de } \\
\text { ovos/postura }\end{array}$ & Fecundidade & $\begin{array}{l}\text { Período de } \\
\text { oviposição }\end{array}$ \\
\hline $\mathrm{D}_{1}$ & $12,6 \pm 0,50 \mathrm{a}$ & $12,7 \pm 0,50 \mathrm{a}$ & $8,4 \pm 0,87 b$ & $33,3 \pm 2,75 \mathrm{a}$ & $268,4 \pm 32,81 \mathrm{~b}$ & $7,7 \pm 0,84 \mathrm{a}$ \\
\hline $\mathrm{D}_{2}$ & $14,1 \pm 0,55 \mathrm{a}$ & $12,5 \pm 0,73 \mathrm{a}$ & $10,7 \pm 0,87 \mathrm{a}$ & $39,5 \pm 2,06 \mathrm{a}$ & $404,4 \pm 25,96 \mathrm{a}$ & $8,9 \pm 0,41 \mathrm{a}$ \\
\hline $\mathrm{D}_{3}$ & $13,3 \pm 0,58 \mathrm{a}$ & $12,1 \pm 0,67 \mathrm{a}$ & $9,0 \pm 0,56 a b$ & $39,4 \pm 1,62 \mathrm{a}$ & $352,0 \pm 21,11 \mathrm{ab}$ & $8,9 \pm 0,49 a$ \\
\hline
\end{tabular}

Médias não seguidas da mesma letra na vertical diferem estatisticamente entre si pelo teste de Tukey em nível de 5\% de probabilidade de erro.

desempenho do inseto quando alimentado com esta dieta, uma vez que, em geral, tanto para imaturos como para adultos cerca de 10 aminoácidos diferentes são indispensáveis ao bom crescimento e desenvolvimento dos mesmos (CHAPMANN, 1982).

A taxa líquida de reprodução $\left(\mathrm{R}_{0}\right.$, também apresentou diferenças em função da dieta, sendo que na dieta $D_{1}$, foi 1,5 vezes menor do que na $D_{2}$ e 1,4 vezes menor do que na $\mathrm{D}_{3}$ (Tabela 5). A razão infinitesimal de aumento $\left(r_{m}\right)$ e a razão finita de aumento (l) foram ligeiramente menor na dieta $D_{1}$, sendo os maiores valores obtidos na dieta $\mathrm{D}_{3}$. Embora o número de indivíduos adicionados à população por fêmea que darão fêmeas $(\lambda)$ tenha sido superior em $\mathrm{D}_{3}$, esse é um ponto positivo para essa dieta, por serem as fêmeas quem garantem o aumento dos descendentes na próxima geração, e quando se avaliou esse parâmetro de forma ampla, junto aos demais $\left(T, R_{0}, r_{m}\right)$ foi possível visualizar que o incremento final esperado na população será expressivo.

\section{CONCLUSÕES}

A dieta à base de feijão carioca, levedura de cerveja e germe de trigo $\left(D_{3}\right)$ favorece o desenvolvimento de Argyrotaenia sphaleropa mais

Tabela 5 - Duração média da geração (T), taxa líquida de reprodução $\left(\mathrm{R}_{0}\right)$, razão infinitesimal de aumento $\left(\mathrm{r}_{\mathrm{m}}\right)$ e razão finita de aumento $(\lambda)$ para Argyrotaenia sphaleropa, criada em três dietas artificiais com fontes protéicas variáveis $\left(\mathrm{D}_{1}\right.$ : feijão branco, germe de trigo, proteína de soja e caseína, $\mathrm{D}_{2}$ : feijão carioca e levedura de cerveja; $\mathrm{D}_{3}$ : feijão carioca, levedura de cerveja e germe de trigo). Temperatura: $25 \pm 1^{\circ} \mathrm{C}$; UR: $65 \pm 10 \%$ e fotofase: $14 \mathrm{~h}$

\begin{tabular}{lcccc}
\hline Dietas & $\mathrm{T}$ (dias) & $\mathrm{R}_{0}$ & $\mathrm{r}_{\mathrm{m}}$ & $\lambda$ \\
\hline $\mathrm{D}_{1}$ & 38,05 & 75,20 & 0,11354 & 1,120 \\
$\mathrm{D}_{2}$ & 39,10 & 112,80 & 0,12087 & 1,128 \\
$\mathrm{D}_{3}$ & 37,39 & 107,95 & 0,12521 & 1,133 \\
\hline
\end{tabular}

do que as dietas à base de feijão branco, germe de trigo, proteína de soja e caseína $\left(\mathrm{D}_{1}\right)$ e feijão carioca, levedura e caseína $\left(\mathrm{D}_{2}\right)$, sendo satisfatória para criação dessa espécie em laboratório.

\section{REFERÊNCIAS BIBLIOGRÁFICAS}

BENTANCOURT, C.; SCATONI, I. Biologia de Argyrotaenia sphaleropa Meyrick (1909) (Lep., Tortricidae) em condiciones de laboratório. Rev Brasil Biol, v.46, p.209-216, 1986.

BENTANCOURT, C. et al. Observaciones sobre la biologia de Argyrotaenia sphaleropa (Meyrick, 1909) (Lepidoptera, Tortricidae) en la zona sur del Uruguay, 1988. Boletim de Investigación, n.13, 12p, 1988.

BENTANCOURT, C. et al. Effects of larval diet on the development and reproduction of Argyrotaenia sphaleropa (Meyrick) (Lepidoptera: Tortricidae). Neotropical Entomology, v.32, n.4, p.551-557, 2003.

BENTANCOURT, C.M.; SCATONI, I. Lepidopteros de importancia economica: reconocimiento, biología y dãnos de las plagas agrícolas y florestales. Montevideo: Agropecuaria Hemisferio Sur SRL, 1995. 122p.

BIEZANKO, C. Olethreutidae, Tortricidae, Phaloniidae, Aegerilidae, Gliphipterygidae, Yponomeutidae, Gelechiidae, Oecophoridae, Xylorictidae, Lithocolletidae, Gesidoseidae, Ridiaschinidae, Acrolophidae, Tineidae et Psychidae da Zona Sueste do Rio Grande do Sul. Ent Agron, p.1-16, 1961.

BIEZANKO, C.M. et al. Lepidoptera del Uruguay, Lista anotada de especies. Revista de la Facultad de Agronomia, v.2, p.3-152, 1957.

CHAPMAN, R.F. The insects sctructure and function. Cambridge : Harvard University, 1982. 919p.

HADDAD, M.L. et al. Modelos bioestatísticos aplicados à entomologia. Piracicaba : ESALQ, 1995. 44p.

HAWTHORNE, D.J. et al. Redbanded leafroller (Lepidoptera: Tortricidae) thermal requirements for development and simulation of within-season phenology in North Carolina. Environ Entomol, v.17, p.40-46, 1988 .

Ciência Rural, v.35, n.2, mar-abr, 2005. 
PANIZZI, A.R.P.; PARRA, J,R.P. Ecologia nutricional de insetos e suas implicações no manejo de pragas. São Paulo : Manole, 1991. 359p.

PARRA, J.R.P. Técnicas de criação de insetos para programas de controle biológico. Piracicaba : FEALQ 1992. $161 \mathrm{p}$.

PARRA, J.R.P. et al. Técnica de criação de Phtheocroa cranades Meyrick (Lepidoptera: Tortricidae) em dieta artificial. Rev Bras Biol, v.55, p.537-543, 1995 .

SAS-STST. The SAS system version 6.12. Carry: SAS, 1998. 584p.
SCATONI, I.B.; BENTANCOURT, C.M. Biología de Eulia salubricola Meyrick (1931) (Lepidoptera, Tortricidae) en condiciones de laboratorio. Uruguay: Facultad de Agronomia, 1988. 12p. (Boletim de Investigación, 11).

SCRIBER, J.M.; SLANSKY, JR. The nutricional ecology of immature insects. Annual Review of Entomology, v.26, p.183-211, 1981 .

SILVEIRA NETO, S. et. al. Manual de ecologia dos insetos. São Paulo : Ceres, 1976. 419p.

SINGH, P. A general purpose laboratory diet mixture for rearing insects. Insect Science and its application, v.4, p.357-362, 1983 